\title{
Competition-free gaps are essential for the germination and recruitment of alpine species along an elevation gradient in the European Alps
}

\author{
Vera Margreiter $^{1} \mathbb{D} \cdot$ Janette Walde $^{2} \mathbb{D} \cdot$ Brigitta Erschbamer $^{1}$ (D)
}

Received: 16 March 2021 / Accepted: 13 July 2021 / Published online: 27 July 2021

(c) The Author(s) 2021

\begin{abstract}
Seed germination and seedling recruitment are key processes in the life cycle of plants. They enable populations to grow, migrate, or persist. Both processes are under environmental control and influenced by site conditions and plant-plant interactions. Here, we present the results of a seed-sowing experiment performed along an elevation gradient (2000-2900 m a.s.l.) in the European eastern Alps. We monitored the germination of seeds and seedling recruitment for 2 years. Three effects were investigated: effects of sites and home sites (seed origin), effects of gaps, and plant-plant interactions. Seeds of eight species originating from two home sites were transplanted to four sites (home site and \pm in elevation). Seed sowing was performed in experimentally created gaps. These gap types ('gap + roots', 'neighbor + roots', and 'no-comp') provided different plant-plant interactions and competition intensities. We observed decreasing germination with increasing elevation, independent of the species home sites. Competition-released gaps favored recruitment, pointing out the important role of belowground competition and soil components in recruitment. In gaps with one neighboring species, neutral plant-plant interactions occurred (with one exception). However, considering the relative vegetation cover of each experimental site, high vegetation cover resulted in positive effects on recruitment at higher sites and neutral effects at lower sites. All tested species showed intraspecific variability when responding to the experimental conditions. We discuss our findings considering novel site and climatic conditions.
\end{abstract}

Keywords Competition $\cdot$ Facilitation $\cdot$ Intra- and interspecific variability $\cdot$ Home-site effect $\cdot$ Seed ecology

\section{Introduction}

Seed germination, seedling establishment, and seedling growth (i.e., 'recruitment', Eriksson and Ehrlén 2008) are crucial for species abundance and population size in a community (Harper 1977; Fenner and Thompson 2005; Donohue et al. 2010; Jiménez-Alfaro et al. 2016). Germination and recruitment are, with some exceptions, commonly linked, but both are equally important for comprehensive insight into species performance (Walck et al. 2011; Mondoni et al. 2015).

Vera Margreiter

vera.margreiter4@gmail.com

1 Department of Botany, University of Innsbruck, Sternwartestrasse 15, 6020 Innsbruck, Austria

2 Department of Statistics, University of Innsbruck, Universitätsstrasse 15, 6020 Innsbruck, Austria
Seed germination and recruitment are strongly governed by environmental conditions (abiotic factors; Graae et al. 2008; Venn and Morgan 2009; Walck et al. 2011; Rosbakh and Poschlod 2015), species-specific characteristics (e.g., seed production and dispersal, dormancy, and local adaptation; Stöcklin and Bäumler 1996; Donohue et al. 2010; Meineri et al. 2013; Fernández-Pascual et al. 2020), and plant-plant interactions (Callaway et al. 2002; Venn et al. 2009; Wright et al. 2014). With ongoing climate warming (Gobiet et al. 2014), uncertainties exist regarding the life stages of plant species in alpine environments due to the influence of temperature changes coupled with lower snow cover, earlier snow melt, and a decrease in precipitation in summer. It has already been shown that changes in snowcover patterns alter conditions for germination and seedling recruitment (Hülber et al. 2011; Briceño et al. 2015). Warmer temperatures may favor some alpine species, as they require relatively high temperatures for seed germination (Graae et al. 2008; Walder and Erschbamer 2015; 
Tudela-Isanta et al. 2018; Fernández-Pascual et al. 2020; Margreiter et al. 2020). Furthermore, seedling recruitment may also be enhanced by higher temperatures (Mondoni et al. 2015) if impeding conditions (e.g., drought in the topsoil layer, frost damage, and heat stress) can be avoided or tolerated (Venn and Morgan 2009; Marcante et al. 2012, 2014)

As a reaction to the novel environmental conditions caused by climate change, plants can either migrate via seeds and track their environmental niche or persist and adjust to new conditions by genetic adaptation or acclimation and plasticity (Stöcklin et al. 2009; Donohue et al. 2010; Alexander et al. 2015, 2018; Anderson and Wadgymar 2020). Alternatively, species may be locally adapted to their currently realized niches (Meineri et al. 2013; Anderson and Wadgymar 2020; Veselá et al. 2020) and consequently demonstrate an advantage of seed germination and recruitment at their home site (i.e., elevation of the mother plant). However, this local adaptation will be suboptimal for species, which are forced to adjust to novel environmental conditions or to migrate to track their realized niche. In contrast, species with high levels of intraspecific trait variability possess high levels of adaptability (Cochrane et al. 2015).

Among the biotic drivers that influence germination and recruitment, plant-plant interactions must be considered (Callaway et al. 2002; Venn et al. 2009; Wright et al. 2014). According to the stress-gradient hypothesis (Bertness and Callaway 1994; Venn et al. 2009; Cavieres et al. 2014; Klanderud et al. 2017), positive interaction (facilitation) occurs when abiotic stress is strong, while negative interaction (competition) prevails when abiotic stress is weak. In mountainous areas, a stress gradient occurs along elevation from the subalpine to nival zones. Temperature decreases by $0.6{ }^{\circ} \mathrm{C} / 100 \mathrm{~m}$ a.s.l. in the European Alps, while wind and radiation increase (Körner 2003; Kuhn et al. 2013). Along these gradients, net plant-plant interactions can be positive, negative, or neutral. Thus, competition or facilitation may prevail or coexist at the same time (Erschbamer et al. 2008; Venn et al. 2009; Cavieres et al. 2014; Wright et al. 2014).

In addition to studies on adult plants, net positive/negative interactions have been shown in seedling growth in different biomes (Ryser 1993; Graae et al. 2008; Venn et al. 2009; Milbau et al. 2009; Cichini et al. 2011; Klanderud et al. 2017). In the European Alps, evidence for plant-plant interaction effects on seed germination and seedling recruitment is still scarce, and such effects have hardly been tested along elevation gradients.

Within experimental gaps using one target species in the center and all neighboring plants removed, Callaway et al. (2002) clearly showed beneficial effects on the leaf number and biomass of target species in the alpine zone worldwide. In contrast, in the subalpine zone, competition by the established plant in the gap prevailed, and negative neighbor effects resulted. A well-established neighbor can provide shelter from strong winds, shade from full radiation exposure, and mitigate temperature extremes for adjacent growing species (i.e., facilitation aboveground; Bertness and Callaway 1994; Cavieres et al. 2014; Hupp et al. 2017). This might be particularly important for alpine seedlings. In contrast, emerging seedlings may have to compete for resources, such as light, water, nutrients, or simply space, with established neighboring plants (i.e., competition aboveand belowground). Here, gaps may offer opportunities for growth and reproduction.

In lowlands and mountain grasslands, high vegetation cover was found to inhibit germination and seedling establishment via light and resource limitations (Ryser 1993; Fenner and Thompson 2005). With increasing elevation, vegetation cover decreases, offering gaps for colonization. However, at high elevations, gaps may expose seeds and seedlings to increased harsh abiotic conditions (i.e., temperature extremes, wind, and drought). This indicates that these 'unprotected' microhabitats could prevent recruitment and growth (Callaway et al. 2002; Anthelme et al. 2012). Therefore, we assume that the initial life stages of plant species will profit from established vegetation (vegetation cover) at high elevations, as we have learned from the stressgradient hypothesis (Callaway et al. 2002; Venn et al. 2009; Anthelme et al. 2014).

In a 2-year experiment, we studied the effects of sites and vegetation cover at different elevations on seed germination and seedling recruitment along an elevation gradient in the European eastern Alps from 2000 to 2900 m a.s.l. (i.e., subalpine to nival zones). We included eight alpine species, considering the dominant alpine life forms (graminoids, herbs, cushion plants, and species propagating via bulbils; Körner 2003; Steiner et al. 2012). The elevation gradient served as a space-for-time substitution for novel environmental conditions, as has been found to be pertinent in other studies (e.g., Callaway et al. 2002; Venn et al. 2009). Seeds were collected in the lower and upper alpine zones $(2300 \mathrm{~m}, 2600 \mathrm{~m}$ a.s.1.) and sown at both sites, as well as in the subalpine zone, thus reflecting future climate, and in the nival zone, thus reflecting cooler conditions than those at the original seed site. We further studied the effects of experimental gaps on germination and recruitment by including three gap types: (1) an aboveground competition-free gap with belowground competition ('gap + roots'); (2) an only one central-plant that was left aboveground gap, according to Callaway et al. (2002; i.e., interaction with one plant and belowground competition; 'neighbor + roots'); and (3) an artificial gap (i.e., no competition and no interaction; 'no-comp'). Until the end of the second year, the experimental gaps were partly overgrown by the adjacent vegetation (overgrowing and clonal ingrowth; Cichini et al. 2011) and/or seedlings from species not sown in the experimental gaps had germinated. Thus, 
recruitment of the sown species might have been influenced by this vegetation cover ('top cover'; Greig-Smith 1983).

The following hypotheses were tested:

H1: We expect that the experimental sites will influence species performance; alpine species will germinate and recruit best at their home sites; at lower and upper experimental sites, species should have weaker germination and recruitment.

$\mathrm{H} 2$ : We assume gap effects and competition at the lowest study site (subalpine zone). There, germination and recruitment should be best in gaps without competition ('no-comp') and to a lesser extent, with only belowground competition ('gap + roots').

H3: We assume gap effects and facilitation for recruitment in gap-type 'neighbor + roots' at the alpine and nival sites, with the central plant providing amelioration from harsh abiotic conditions. Similarly, a facilitation effect on recruitment is assumed when vegetation cover increases at the highest elevations.

\section{Materials and methods}

\section{Study area and experimental sites}

The study area was located in the Oetz Valley, central European Alps (near Obergurgl, Austria). The average annual air temperature in Obergurgl (1938 m a.s.1., $11^{\circ} 01.5^{\prime} \mathrm{E}$, $46^{\circ} 52^{\prime} \mathrm{N}$ ) is $2.8^{\circ} \mathrm{C}$; annual precipitation averages $848 \mathrm{~mm}$, with the highest precipitation occurring in August (Kuhn et al. 2013).

The experiment was carried out at four sites along an elevation gradient from 2000 to $2900 \mathrm{~m}$ a.s.l. (subalpine to nival zone), spanning the lower alpine (2300 $\mathrm{m}$ a.s.1.) and upper alpine (2600 $\mathrm{m}$ a.s.l.) zones (Table 1, Fig. 1a, b). The vegetation along the elevation gradient varied from subalpine meadows dominated by Festuca rubra and Potentilla aurea at the $2000 \mathrm{~m}$ site (total cover: $90 \%$ ), to Nardus stricta grassland at the lower alpine site $(2300 \mathrm{~m}$, total cover: $80 \%)$, to Carex curvula grassland at the upper alpine site $(2600 \mathrm{~m}$, total cover: $70 \%$ ), and to open vegetation at the nival site at $2900 \mathrm{~m}$ a.s.l. (total cover: 40\%; Fig. 1b). The total vegetation cover at each site was estimated as the average site cover, derived from $3 \times 1 \mathrm{~m}^{2}$ plot observations (Margreiter, pers. observation); see Mayer and Erschbamer (2017) for detailed vegetation descriptions at $2300 \mathrm{~m}$ and $2600 \mathrm{~m}$ a.s.l in the study area.

The four experimental sites were chosen as homogeneously as possible regarding the site vegetation (Table 1). The sites were flat with an inclination below $10^{\circ}$ to minimize the effect of ground movement from rain or freeze-thaw events. The sites at $2000 \mathrm{~m}, 2300 \mathrm{~m}$, and $2600 \mathrm{~m}$ a.s.l. were fenced to exclude grazers.

\section{Study species and seed collection}

We used eight alpine species in the study area as target species (Table 2), including functional groups (herbs, graminoids, and cushion plants), two different life forms (hemicryptophytes and chamaephytes), and two different dispersal modes (seeds and bulbils). All species were perennials, i.e., four hemicryptophytes (two herbs: Homogyne alpina L. and Leucanthemopsis alpina L.; two graminoids: Agrostis rupestris All. and Poa alpina L.); two chamaephytes (i.e., cushion plants: Silene acaulis ssp. exscapa (L.) J. Braun and Minuartia sedoides L.), and two species reproducing via bulbils (Persicaria vivipara (L.) Ronse

Table 1 Environmental description of the gradient at four experiment sites located in the European eastern Alps, Austria

\begin{tabular}{|c|c|c|c|c|c|c|c|c|c|}
\hline $\begin{array}{l}\text { Experi- } \\
\text { ment site } \\
\text { (a.s.1.) }\end{array}$ & Elevation zone & Site vegetation & Year & $\begin{array}{l}\text { Mean } \\
\mathrm{T}\left({ }^{\circ} \mathrm{C}\right) \\
\text { JJA }\end{array}$ & $\operatorname{Max} \mathrm{T}\left({ }^{\circ} \mathrm{C}\right) \mathrm{JJA}$ & $\operatorname{Min} \mathrm{T}\left({ }^{\circ} \mathrm{C}\right) \mathrm{JJA}$ & $\begin{array}{l}\text { Mean SWP } \\
(-M P a) J J A\end{array}$ & $\begin{array}{l}\text { Max SWP } \\
(-\mathrm{MPa}) \\
\text { JJA }\end{array}$ & $\begin{array}{l}\text { Min SWP } \\
(-\mathrm{MPa}) \\
\text { JJA }\end{array}$ \\
\hline \multirow[t]{2}{*}{$2000 \mathrm{~m}$} & \multirow[t]{2}{*}{ Subalpine } & \multirow{2}{*}{$\begin{array}{l}\text { Subalpine meadow } \\
\text { dominated by } \\
\text { Festuca rubra and } \\
\text { Potentilla aurea }\end{array}$} & 2017 & 13.4 & 34.7 & 0.1 & 0.1 & 1.4 & 0.02 \\
\hline & & & 2018 & 13.8 & 28.5 & 0.4 & 0.7 & 1.4 & 0.02 \\
\hline \multirow[t]{2}{*}{$2300 \mathrm{~m}$} & \multirow[t]{2}{*}{ Lower alpine } & \multirow{2}{*}{$\begin{array}{l}\text { Nardus stricta grass- } \\
\text { land }\end{array}$} & 2017 & 13.1 & 30.9 & 1.9 & 0.02 & 0.03 & 0.01 \\
\hline & & & 2018 & 13.4 & 26.3 & 2.6 & 0.7 & 1.4 & 0.02 \\
\hline \multirow[t]{2}{*}{$2600 \mathrm{~m}$} & \multirow[t]{2}{*}{ Upper alpine } & \multirow{2}{*}{$\begin{array}{l}\text { Carex curvula grass- } \\
\text { land }\end{array}$} & 2017 & 11.5 & 30.1 & 0.6 & 0.02 & 0.1 & 0.02 \\
\hline & & & 2018 & 12.6 & 32.8 & 0.9 & 0.1 & 1.4 & 0.02 \\
\hline \multirow[t]{2}{*}{$2900 \mathrm{~m}$} & \multirow[t]{2}{*}{ Nival } & \multirow{2}{*}{$\begin{array}{l}\text { Open pioneer vegeta- } \\
\text { tion }\end{array}$} & 2017 & 8.7 & 42.7 & -3.0 & $\mathrm{Na}$ & $\mathrm{Na}$ & $\mathrm{Na}$ \\
\hline & & & 2018 & 8.2 & 30.1 & -0.1 & 0.03 & 0.1 & 0.02 \\
\hline
\end{tabular}

Daily mean maximum (Max), average (Mean) and mean minimum (Min) soil temperature (T) and soil water potential (SWP) in $2 \mathrm{~cm}$ depth, given for the months June, July, and August (JJA), which represent the main growing seasons

a.s.l. above sea level. Na not available 
a

Difference from species home site ( $m$ a.s.I.)
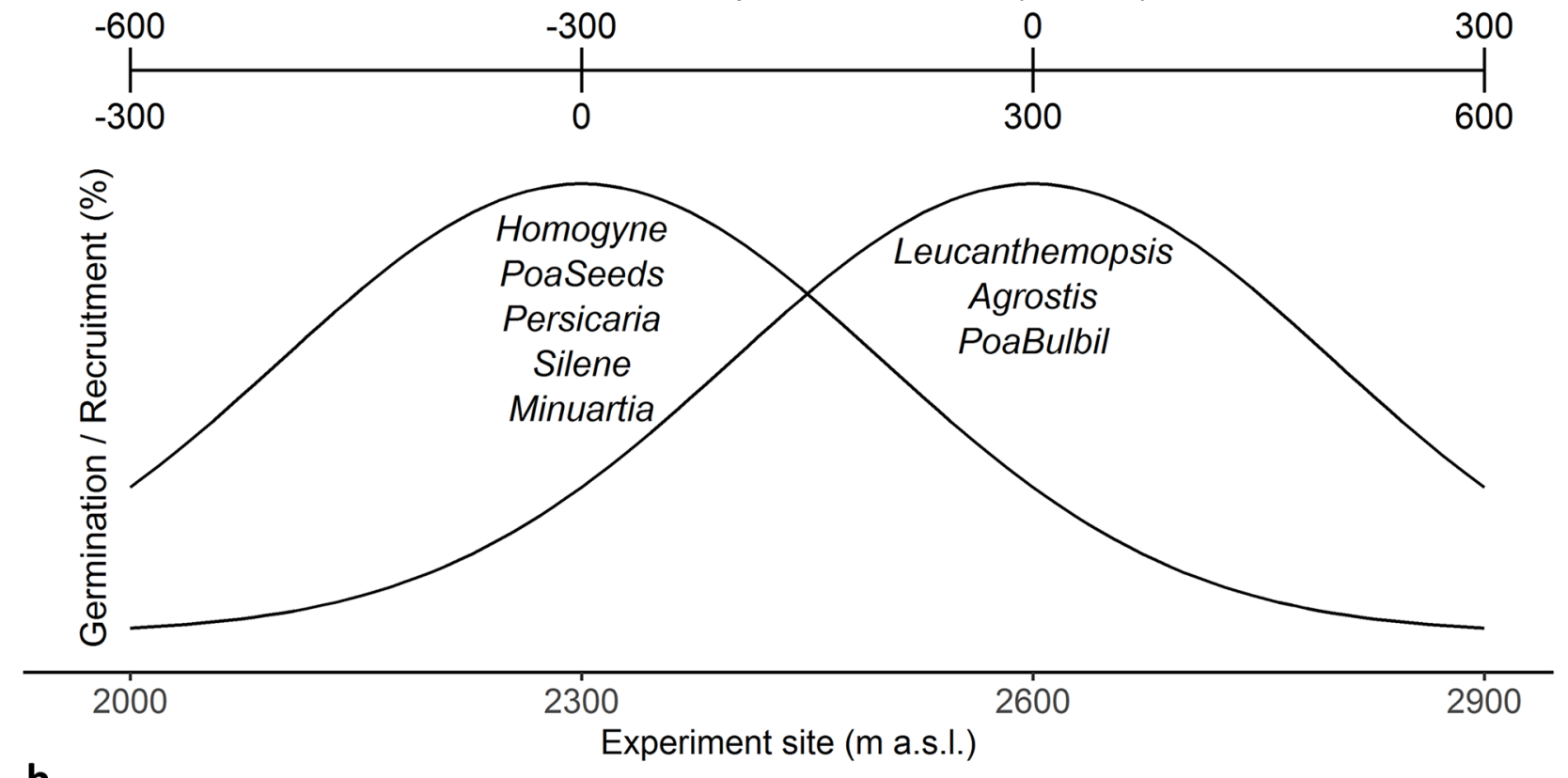

b
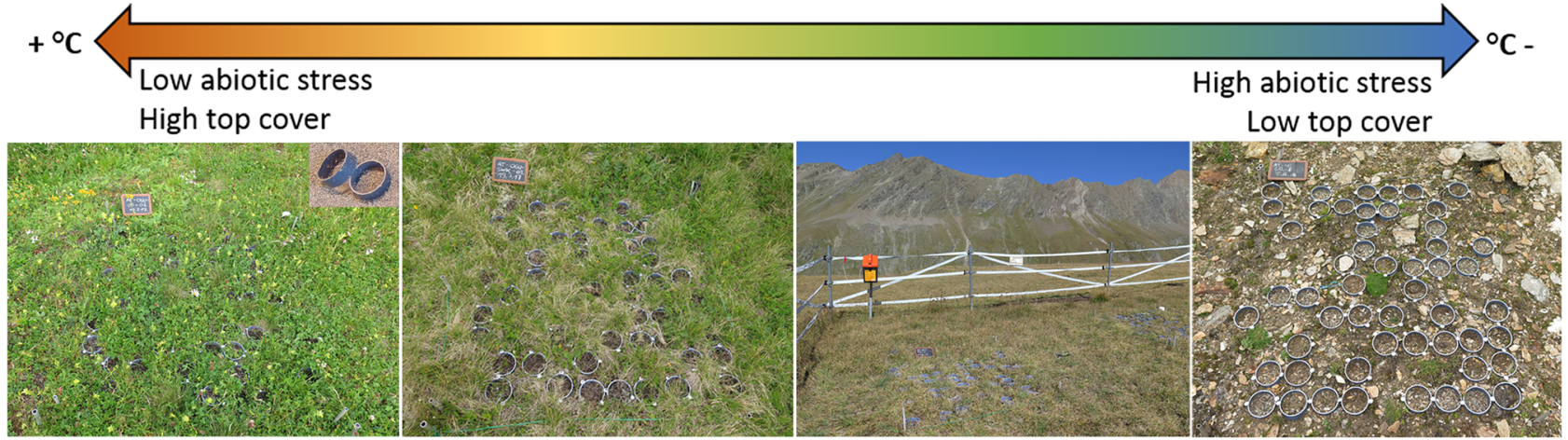

C
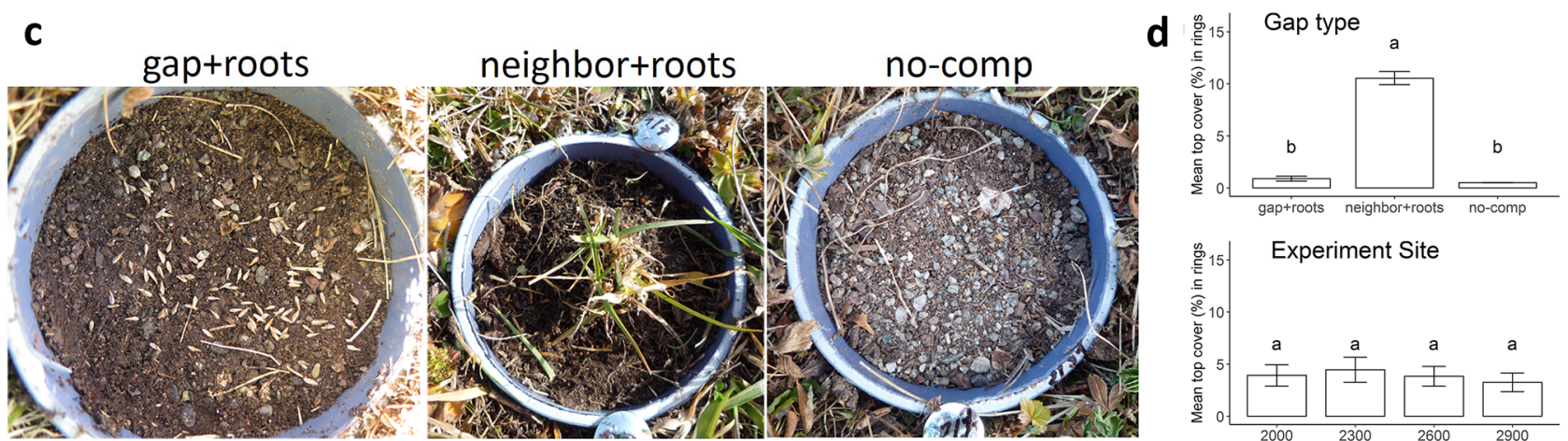

Fig. 1 a Experimental design. Seed collections at $2300 \mathrm{~m}$ and $2600 \mathrm{~m}$ a.s.l. represent the locations with optimal seed production of the target species, indicated in the theoretical diagram as their home sites. b The experiment was performed along an abiotic stressgradient at four experiment sites. Germination and recruitment were monitored for 2 years. Seed sowing was done in experimentally created gaps. c The effects of experimental gaps on germination and recruitment were studied by including three gap types: 'gap + roots': aboveground competition-free gap with belowground competition; 'neighbor + roots': only one central-plant that was left aboveground gap; and 'no-comp': artificial gap (i.e., no competition and no interaction;). d Gap-type manipulations provided zero aboveground cover in 'gap + roots' and 'no-comp', and $10.5 \%$ top cover in 'neighbor + roots' (d, upper panel). Gap-type manipulations were similar at each experiment site (d, lower panel) 
Table 2 Study species in the experiment, in order of Fig. 1a, with species from home site $2300 \mathrm{~m}$ a.s.1. first, and their affiliation to families (Fischer et al. 2008)

\begin{tabular}{lllll} 
Species & Family & Distribution range & Seeds & Home site (m a.s.1.) \\
\hline Homogyne alpina & Asteraceae & coll-mont-suba-alp-niv & achenes & 2300 \\
Poa alpina Seeds & Poaceae & coll-mont-suba-alp-niv & caryopses & 2300 \\
Persicaria vivipara & Polygonaceae & mont-suba-alp & bulbils & 2300 \\
Silene exscapa & Caryophyllaceae & suba-alp-niv & seeds & 2300 \\
Minuartia sedoides & Caryophyllaceae & suba-alp-niv & seeds & 2300 \\
Leucanthemopsis alpina & Asteraceae & mont-suba-alp-niv & achenes & 2600 \\
Agrostis rupestris & Poaceae & mont-suba-alp-niv & caryopses & 2600 \\
Poa alpina Bulbil & Poaceae & mont-suba-alp-niv & bulbils & 2600 \\
\hline
\end{tabular}

$\mathrm{SE}=$ standard error; $\mathrm{Na}=$ Not available

Species distribution ranges (Aeschimann et al. 2004) are listed in elevation zones as colline (coll), montane (mont), subalpine (suba), alpine (alp), and nival (niv); species main distribution is indicated in bold. Diaspores are called 'seeds' for simplicity. Seed collections were made at two elevations that consequently represent a species home site (last column in table). Species with home site at $2300 \mathrm{~m}$ have no background color; species with home site at $2600 \mathrm{~m}$ have a grey background

Decr. and the viviparous form of Poa alpina L.), both hemicryptophytes. All species have their main center of distribution (Aeschimann et al. 2004) and their optimum seed production (known by multi-year seed collections and germination studies and by a long-term study; Mayer and Erschbamer 2017) in the lower (2300 m a.s.l.) and upper alpine zones ( $2600 \mathrm{~m}$ a.s.1.). One of the main reasons for selecting these target species was that they produce sufficient amounts of seeds, and all have good germination potential in the field. Nomenclature and life forms follow Fischer et al. (2008). Hereafter, species names refer to genus names and PoaSeeds or PoaBulbil to distinguish between the two reproductive modes of Poa alpina. Furthermore, the term species includes all species plus PoaBulbil.

The target species produce different types of diaspores (achenes, caryopses, seeds, or bulbils), hereafter called 'seeds' for simplicity. Seeds of each species were collected at the time of maturity from 23rd August to 29th September 2016 (collection date is species-specific), i.e., when the species would naturally disperse in the study area (Erschbamer and Margreiter, pers. observation). Seeds were collected at two elevations, $2300 \mathrm{~m}$ (five species) and $2600 \mathrm{~m}$ a.s.l. (three species) to investigate home-site effects (Table 1, Fig. 1a) and specifically to gain fully ripened seeds that were able to germinate.

For each species, seeds from two to four populations and at least ten individuals were harvested. After collection, seeds were kept dry in paper bags, and bulbils were kept moist in plastic bags at room temperature until processing was completed (i.e., storage duration from 68 to 85 days depending on harvest date). Processing included seed cleaning and preparation of portions of 100 seeds for sowing in the field.

\section{Field design}

Seeds collected at $2300 \mathrm{~m}$ a.s.l. were transplanted to one lower $(-300 \mathrm{~m})$ site, the home site, and two higher $(+300 \mathrm{~m}$ and $+600 \mathrm{~m}$ ) sites, and species collected at $2600 \mathrm{~m}$ a.s.1. were sown at two lower $(-300 \mathrm{~m}$ and $-600 \mathrm{~m})$ sites, the home site, and one higher $(+300 \mathrm{~m})$ site (Fig. 1a). To provide a comparable sowing-area size, we created experimental gaps using rings (Fig. 1b, c) made from HT-duct pipes with a $9 \mathrm{~cm}$ diameter. An HT-duct pipe (similar to a PVC pipe but more resistant to environmental damage, such as bending due to high temperatures and radiation) was cut into slices that were $3.5 \mathrm{~cm}$ wide resulting in rings (Fig. 1b, small picture inset). These rings were sunk into the ground to the surface level and fixed with nails on the outside to prevent potential movement.

To study plant-plant interactions (gap effects) on germination and recruitment along the elevation gradient, the rings were manipulated according to three gap types (Fig. 1c): 'gap + roots', 'neighbor + roots', and 'no-comp'. In rings assigned to 'gap + roots', all aboveground biomass was removed by pulling the aboveground plant parts out by hand and/or clipping them off; the belowground parts (i.e., roots and local soil) remained untouched (similar to Venn et al. 2009), providing belowground competition for emerging seedlings. In rings assigned to 'neighbor + roots', the aboveground biomass was reduced to only one centralplant that was left in the ring, similar to the Callaway et al. (2002) experiments; belowground parts were untouched. Here, effects of plant-plant interactions were assumed, i.e., aboveground negative (e.g., shade or space), positive (e.g., wind protection, amelioration of temperature extremes or drought), or neutral effects. The specific central plants remaining in the rings differed along the gradient due to natural variation in the local vegetation (see Supp. Table S1). In 
rings assigned to 'no-comp', above- and belowground biomass was removed. This was performed using a weed picker, and excavating all biomass from the previous setup ring at ground level; resulting in a hole within the ring. This hole was then filled with a sterile alpine soil-mixture (5:2:2:2:1 leaf mold:ground earth:peat:silicate sand:lava) provided by the Botanical Garden in Innsbruck. This was performed for two reasons. First, this was the easiest choice in achieving a 'no-comp' gap type and sterilized soil has been used in previous studies (e.g., Cichini et al. 2011). Second, the vast amount of local soil material needed would have led to destruction of the sensitive local alpine vegetation in the study area, which was avoided using an artificial alpine soil mixture. Notably, microorganisms were able to invade the soil in the rings because the rings were open and had a low height (Yang and van Elsas 2018).

The specific positioning of the individual rings at each experimental site, the individual gap preparation and the specific species to be sown in the ring were fully randomized. Four rings per species and gap type were placed at each elevation.

We estimated the vegetation 'top cover' in each ring (top cover estimation in \% based on Greig-Smith 1983) at the start and end of the experiment via pictures. At the start of the experiment, one-way ANOVA and Tukey post hoc tests were used to compare the experimental setup. Gap types 'gap + roots' vs 'no-comp' were not significantly different from each other regarding top cover $(F=868.4$, Tukey test $p=0.318$; Fig. $1 \mathrm{~d}$, upper panel); in contrast, vegetation top cover of 'neighbor + roots' was different $(10.5 \pm 2.6 \%$, $p<0.001)$. There were no differences in vegetation cover across elevation gradient at the start of the experiment $(F=0.892, p=0.434$; Fig. 1d, lower panel). During the 2 years of the experiment, vegetation grew naturally, i.e., growth of the target seedlings, growth of the central plants in the rings, growth of other seedlings, and growth of the local vegetation surrounding the experimental rings. The vegetation top cover of the rings at the end of the experiment was used as an explanatory variable (see "Data analysis") to evaluate possible effects on recruitment at each site (in regard to $\mathrm{H} 3$ and the stress-gradient hypothesis).

\section{Sowing and monitoring}

In each prepared ring, 100 seeds of one species were sown between $30^{\text {th }}$ October and $16^{\text {th }}$ November 2016 and were slightly covered with matching soil to ensure their placement and prevent them from being blown away. The timing of sowing exposed the seeds to natural cold-wet stratification during the following winter period (Schwienbacher et al. 2011; Tudela-Isanta et al. 2018). By the time of sowing, the soil was already covered by snow at the $2900 \mathrm{~m}$ site; therefore, target seeds were buried under snow at $2600 \mathrm{~m}$ a.s.l. in fine mashed synthetic bags to expose them to the same natural cold-wet stratification. These seeds were then sown at $2900 \mathrm{~m}$ a.s.l. after snowmelt on 3rd July 2017.

After the first winter, the $2900 \mathrm{~m}$ site was partly damaged by a marmot; thus, eight additional rings were placed there.

The counting of germinated seeds and growing seedlings began after snowmelt at each experimental site and was repeated approximately every 4 weeks during the entire summer period in 2017 (24th April-26th October). This was performed to follow up on as many germination events as possible, as germination is sometimes spread across the summer or is even postponed into autumn in several species (Mondoni et al. 2015). The monitoring of germination and seedling growth was also conducted in the second year, twice at each experimental site (2nd May-6th August 2018) to follow up on dormant seeds (Shimono and Kudo 2003; Fernández-Pascual et al. 2020). A total of 387 rings could be monitored throughout the 2 years of the experiment, containing 38,685 seeds sown. In cases when the central plant in 'neighbor + root' rings died, these rings were excluded from further analyses.

\section{Abiotic microenvironment}

Abiotic variables were measured at each site from 25th October 2016 to 6th August 2018, i.e., 650 days, to confirm the stress gradient along the experimental elevation profile. Soil temperature was measured at a $2 \mathrm{~cm}$ depth every $15 \mathrm{~min}$ via TidbiT v2 data loggers (Onset Computer Corporation, Bourne, MA, USA). Furthermore, soil water potential (SWP) was measured at a $2 \mathrm{~cm}$ soil depth in hourly intervals by a MicroLog SP3 (Environmental Measuring Systems, Brno, Czech Republic). These data represent conditions for seed germination close to the soil surface and conditions for seedling growth, as roots protruded in the upper soil layer. Daily mean maximum, average and mean minimum values for soil temperature and SWP were calculated for the growing season (June-August; Table 1, and see Supp. Fig. S1 for illustrations).

Soil samples from the local soil and from the nonlocal soil mixture were collected at the end of the experiment to check the potential impact of the soil conditions. Soil $\mathrm{pH}$ and carbon-to-nitrogen ratios $(\mathrm{C} / \mathrm{N})$ were determined by the Department of Microbiology, University of Innsbruck (measured on a CN analyzer Truspec CHN Macro, Leco, MI, USA, using oven-dried soil). Soil $\mathrm{pH}$ was highest in the soil-mixture soil $(\mathrm{pH}>6)$ and at the $2900 \mathrm{~m}$ site $(\mathrm{pH}>5.4)$ in local soil; it was lowest at $2300 \mathrm{~m}$ a.s.l. $(\mathrm{pH} \leq 4.1$; Table 3$) . \mathrm{C} / \mathrm{N}$ ratios were approximately the same at all experimental sites in the local soil and soil mixture from 2000 to $2600 \mathrm{~m}$ a.s.l. $(23.3<\mathrm{C} / \mathrm{N}<24.3)$. Only at the 
Table 3 Soil components at the experimental sites, determined at the end of the experiment

\begin{tabular}{lllll}
\hline Site (m a.s.l.) & pH local soil & $\begin{array}{l}\mathrm{pH} \text { soil- } \\
\text { mixture }\end{array}$ & C/N local soil & $\begin{array}{l}\mathrm{C} / \mathrm{N} \text { soil- } \\
\text { mixture }\end{array}$ \\
\hline 2000 & 4.51 & 6.18 & 24.21 & 23.92 \\
2300 & 4.04 & 6.17 & 23.38 & 24.35 \\
2600 & 4.10 & 6.29 & 24.25 & 24.26 \\
2900 & 5.78 & 6.48 & 14.47 & 21.06 \\
\hline
\end{tabular}

a.s.l. = above sea level. $\mathrm{C} / \mathrm{N}=$ carbon-to-nitrogen ratio

$2900 \mathrm{~m}$ site was the $\mathrm{C} / \mathrm{N}$ ratio in the local soil lower (14.5) than that in the soil mixture (21.1; Table 3).

The data on environmental conditions (e.g., temperature, soil components, and local vegetation) highlight differences in the experimental sites across the elevation stress gradient. Hence, 'site' was used as a factor variable in the analyses (i.e., beta regression).

\section{Data analysis}

Germination was calculated as the proportion from the maximum number of germination events observed divided by the initial number of seeds sown. In the following sections, germination refers to this relative germination proportion. Seedlings that survived until the end of the experiment were counted as recruited. Seedling recruitment was calculated as the proportion of recruited seedlings divided by the initial number of seeds sown.

Germination and seedling recruitment were separately analyzed via beta regression models using a logit link (package 'betareg'; Cribari-Neto and Zeileis 2010). Beta regression models are suitable for variables within a range of zero to one and allow heteroscedasticity and skewness. To allow for the extremes, zeroes and ones, in the dependent variables (germination and recruitment), we transformed each variable (y) as suggested by Smithson and Verkuilen (2006), i.e., $(y \cdot(n-1)+0.5) / n$, where $n$ is the sample size. Contrast coding (Levy 2014) and likelihood ratio tests were used to test the model terms (package 'Imtest'; Hothorn et al. 2019). A significance level of 5\% was chosen for all models, and model assumptions were checked via residual diagnostic plots, which were met in all cases.

The models included the following factors: site (2000, 2300, 2600, and $2900 \mathrm{~m}$ ), gap type ('gap + roots', neighb or + roots', and 'no-comp'), species (Agrostis, Homogyne, Leucanthemopsis, Minuartia, Persicaria, PoaBulbil, PoaSeeds, and Silene), and all interactions. Post hoc group comparisons (Bonferroni method) were conducted between site levels to evaluate the home-site effect on germination and recruitment and between gap-type levels at each experimental site (depending on species) to test for the gap effects and plant-plant interactions in regard to the stress-gradient hypothesis. The package 'emmeans' (Lenth et al. 2019) was used to perform all post hoc tests, with confidence level and $\mathrm{p}$ value adjustments by Bonferroni corrections.

To evaluate the effect of general vegetation growth over 2 years on seedling recruitment, the vegetation top cover per ring was used as a covariate in an additional beta regression model, together with the factor variable 'site' and their interaction.

All analyses were performed using R (version 3.6.3, R Core Team 2020) and RStudio (version 1.3.1093, RStudio Team 2020). We used the package 'tidyverse' (Wickham et al. 2019) for data handling. Figures were produced using the packages 'ggplot2' (within 'tidyverse'; Wickham et al. 2019) and 'cowplot' (Wilke 2018).

\section{Results}

From a total 38,685 seeds sown in the field, ca. 35\% germinated, out of which 6207 seedlings were recruited. The largest portion of these seeds germinated after snowmelt in the first year, but several species spread their germination over the first summer period (Minuartia, Agrostis, Silene, and PoaSeeds). Germination events were also recorded in the second summer, especially at the uppermost experimental site (PoaSeeds, Silene, Minuartia, Leucanthemopsis, and Agrostis); see Supp. Fig. S2.

\section{Site and home-site effects}

Germination (i.e., proportion of germination events from initial number of seeds sown; relative \%) was significantly different across sites $\left(\chi^{2}=430.0, p<0.001\right.$; Table 4$)$ and among species $\left(\chi^{2}=47.2, p<0.001\right.$; Table 4$)$, and the interaction between site*species was significant $\left(\chi^{2}=298.6, p<0.001\right.$; Table 4). The highest germination was at the $2000 \mathrm{~m}$ site $(51.2 \pm 2.5 \%)$, with a continuous decrease toward the $2900 \mathrm{~m}$ site (13.8 $\pm 1.3 \%$; Table 5; Fig. 2a). At the site level, post hoc tests of the beta regression demonstrated significant germination decreases with increasing elevation and no homesite effects (Supp. Table S2a). Compared with the lowest site, total germination was significantly less for species from the home site at $2300 \mathrm{~m}(40.6 \pm 2.7 \%)(p=0.001$; Supp. Table S2a), and for species from the home site at $2600 \mathrm{~m}$ $(68.8 \pm 3.0 \%)(p<0.001 ;$ Supp. Table S2a).

At the species level, from the $2300 \mathrm{~m}$ home-site group, only Persicaria and PoaSeeds had a significantly higher proportion of germination at their home site compared with the other sites (Supp. Table S3a), with $37.4 \pm 5.0 \%$ for Persicaria and $28.7 \pm 4.0 \%$ for PoaSeeds (Table 5). Leucanthemopsis and PoaBulbil germinated significantly better at their home site than at the uppermost site 
Table 4 ANOVA-summary of beta regression models testing germination and recruitment in response to the factors site (i.e., experimental sites incl. home sites), gap type, species, and interaction terms

\begin{tabular}{|c|c|c|c|c|c|c|}
\hline & \multicolumn{3}{|c|}{ Germination } & \multicolumn{3}{|c|}{ Recruitment } \\
\hline & $D f$ & Chisq & $p$ value & $D f$ & Chisq & $p$ value \\
\hline Site (S) & 3 & 430.02 & $<0.001$ & 3 & 131.16 & $<0.001$ \\
\hline Gap type $(\mathrm{G})$ & 2 & 15.19 & 0.001 & 2 & 27.67 & $<0.001$ \\
\hline Species (Sp) & 7 & 347.16 & $<0.001$ & 7 & 139.93 & $<0.001$ \\
\hline $\mathrm{S} \times \mathrm{G}$ & 6 & 77.45 & $<0.001$ & 6 & 59.49 & $<0.001$ \\
\hline $\mathrm{S} \times \mathrm{Sp}$ & 21 & 298.60 & $<0.001$ & 21 & 189.90 & $<0.001$ \\
\hline Gx Sp & 14 & 29.85 & 0.008 & 14 & 39.67 & $<0.001$ \\
\hline \multirow[t]{2}{*}{$S \times G \times S p$} & 42 & 94.15 & $<0.001$ & 42 & 64.89 & 0.013 \\
\hline & \multicolumn{3}{|c|}{ Pseudo R-squared: 0.81} & \multicolumn{3}{|c|}{ Pseudo R-squared: 0.62} \\
\hline
\end{tabular}

$D f$ degrees of freedom, Chisq value of the test statistic

Table 5 Percentages of germination and recruitment (means \pm standard error: total amount; amount per home site $2300 \mathrm{~m}$ and $2600 \mathrm{~m}$; amount per species) along the experimental sites (2000, 2300, 2600, and $2900 \mathrm{~m}$ ) and across the gap types ('gap + roots', 'neighbor + roots', 'no-comp')

\begin{tabular}{|c|c|c|c|c|c|c|c|}
\hline \multirow[b]{2}{*}{ Germination $(\% \pm \mathrm{SE} \%)$} & \multicolumn{4}{|c|}{ Experiment sites (a.s.1.) } & \multicolumn{3}{|c|}{ Gap type } \\
\hline & $2000 \mathrm{~m}$ & $2300 \mathrm{~m}$ & $2600 \mathrm{~m}$ & $2900 \mathrm{~m}$ & gap+roots & neighbor+roots & no-comp \\
\hline Total per factor & $51.2 \pm 2.5(\mathrm{a})$ & $44.5 \pm 2.8(\mathrm{~b})$ & $30.6 \pm 2.5(\mathrm{c})$ & $13.8 \pm 1.3(\mathrm{~d})$ & $32.0 \pm 2.3(\mathrm{a})$ & $33.3 \pm 2.2(\mathrm{a})$ & $39.4 \pm 2.6$ (a) \\
\hline Species home site 2300 & $40.6 \pm 2.7$ & $34.3 \pm 2.6$ & $22.6 \pm 2.8$ & $11.9 \pm 1.6$ & $24.9 \pm 2.3$ & $25.3 \pm 2.0$ & $31.8 \pm 3.0$ \\
\hline Homogyne & $37.3 \pm 2.4$ & $28.2 \pm 6.0$ & $6.8 \pm 1.9$ & $2.9 \pm 0.7$ & $14.4 \pm 3.9$ & $17.0 \pm 3.2$ & $25.0 \pm 6.1$ \\
\hline PoaSeeds & $20.0 \pm 2.2$ & $28.7 \pm 4.0$ & $5.8 \pm 1.4$ & $27.1 \pm 4.2$ & $18.6 \pm 4.0$ & $23.1 \pm 2.7$ & $20.1 \pm 3.9$ \\
\hline Persicaria & $24.0 \pm 4.1$ & $\mathbf{3 7 . 3} \pm \mathbf{5 . 0}$ & $18.1 \pm 5.7$ & $2.0 \pm 0.8$ & $15.2 \pm 3.0$ & $21.2 \pm 4.8$ & $26.6 \pm 6.4$ \\
\hline Silene & $57.5 \pm 4.3$ & $34.2 \pm 7.8$ & $29.7 \pm 5.3$ & $13.6 \pm 1.7$ & $31.9 \pm 4.8$ & $27.0 \pm 4.7$ & $41.6 \pm 7.9$ \\
\hline Minuartia & $64.3 \pm 3.7$ & $43.7 \pm 6.3$ & $52.6 \pm 3.6$ & $11.4 \pm 1.7$ & $43.9 \pm 6.4$ & $37.9 \pm 4.9$ & $47.3 \pm 6.8$ \\
\hline Species home site 2600 & $68.8 \pm 3.0$ & $61.4 \pm 4.8$ & $43.9 \pm 3.9$ & $16.8 \pm 2.4$ & $44.2 \pm 4.3$ & $46.0 \pm 4.1$ & $51.9 \pm 4.3$ \\
\hline Leucanthemopsis & $78.8 \pm 2.8$ & $57.5 \pm 5.3$ & $55.8 \pm 3.7$ & $22.9 \pm 3.9$ & $49.3 \pm 6.3$ & $46.1 \pm 5.6$ & $62.4 \pm 5.8$ \\
\hline Agrostis & $49.2 \pm 4.6$ & $37.8 \pm 8.0$ & $16.4 \pm 3.8$ & $23.6 \pm 3.4$ & $25.8 \pm 5.1$ & $33.6 \pm 5.3$ & $35.9 \pm 5.9$ \\
\hline PoaBulbil & $78.5 \pm 2.3$ & $89.1 \pm 2.2$ & $59.4 \pm 4.0$ & $3.1 \pm 1.1$ & $56.8 \pm 8.8$ & $58.3 \pm 8.9$ & $57.4 \pm 8.9$ \\
\hline \multicolumn{8}{|l|}{ Recruitment $(\% \pm \mathrm{SE} \%)$} \\
\hline Total per factor & $13.0 \pm 1.5(\mathrm{~A})$ & $27.7 \pm 2.0(B)$ & $11.3 \pm 1.6(\mathrm{~A})$ & $12.3 \pm 1.3(\mathrm{~A})$ & $12.0 \pm 1.1(\mathrm{~A})$ & $14.0 \pm 1.2(\mathrm{~A})$ & $22.4 \pm 2.0(B)$ \\
\hline Species home site 2300 & $7.8 \pm 1.0$ & $26.3 \pm 2.7$ & $5.8 \pm 1.1$ & $10.3 \pm 1.5$ & $10.1 \pm 1.2$ & $10.6 \pm 1.4$ & $17.1 \pm 2.3$ \\
\hline Homogyne & $1.5 \pm 0.8$ & $19.5 \pm 6.2$ & $4.4 \pm 1.7$ & $2.7 \pm 0.7$ & $3.0 \pm 0.8$ & $5.3 \pm 1.4$ & $12.8 \pm 5.3$ \\
\hline PoaSeeds & $12.9 \pm 1.8$ & $26.2 \pm 4.1$ & $2.9 \pm 1.2$ & $25.6 \pm 3.6$ & $15.8 \pm 3.5$ & $20.1 \pm 3.0$ & $15.7 \pm 4.0$ \\
\hline Persicaria & $3.0 \pm 0.7$ & $17.8 \pm 5.9$ & $8.1 \pm 2.9$ & $1.5 \pm 0.8$ & $4.2 \pm 1.0$ & $2.2 \pm 1.0$ & $16.2 \pm 4.8$ \\
\hline Silene & $11.3 \pm 2.7$ & $26.5 \pm 6.1$ & $5.8 \pm 2.2$ & $12.1 \pm 2.0$ & $12.3 \pm 2.2$ & $8.4 \pm 2.0$ & $20.8 \pm 2.2$ \\
\hline Minuartia & $10.2 \pm 2.8$ & $41.7 \pm 5.7$ & $7.9 \pm 3.1$ & $7.5 \pm 1.6$ & $15.4 \pm 3.8$ & $14.4 \pm 3.9$ & $20.6 \pm 6.3$ \\
\hline Species home site 2600 & $21.6 \pm 3.3$ & $30.1 \pm 3.0$ & $20.4 \pm 3.5$ & $15.5 \pm 2.3$ & $15.2 \pm 2.1$ & $19.4 \pm 2.1$ & $31.2 \pm 3.3$ \\
\hline Leucanthemopsis & $19.9 \pm 6.6$ & $32.1 \pm 5.4$ & $28.3 \pm 6.0$ & $22.3 \pm 3.8$ & $16.9 \pm 3.6$ & $21.5 \pm 3.6$ & $39.2 \pm 5.2$ \\
\hline Agrostis & $6.3 \pm 1.7$ & $26.5 \pm 5.4$ & $3.4 \pm 1.2$ & $21.3 \pm 3.4$ & $9.4 \pm 2.7$ & $15.4 \pm 3.2$ & $18.3 \pm 4.8$ \\
\hline PoaBulbil & $38.7 \pm 2.6$ & $31.8 \pm 4.9$ & $29.5 \pm 6.3$ & $1.8 \pm 1.0$ & $18.9 \pm 4.4$ & $21.3 \pm 3.9$ & $36.1 \pm 5.7$ \\
\hline
\end{tabular}

Highest values are indicated in bold

Species with home site $2300 \mathrm{~m}$ have no background color; species with home site $2600 \mathrm{~m}$ have a grey colored background. For $p$ values regarding home-site effects, see Fig. 2a, Supp. Table S2a, Supp. Table S3. For p values regarding gap type effects, see Fig. 2b, Supp. Table S2b, Supp. Table S4

( $p<0.001$; Supp. Table S3a), but Leucanthemopsis had the highest germination at the $2000 \mathrm{~m}$ site (ca. 79\%), and PoaBulbil germinated best at $2300 \mathrm{~m}$ (ca. 89\%, Table 5).

Recruitment was significantly different across sites $\left(\chi^{2}=131.2, p<0.001\right.$; Table 4$)$ and among species $\left(\chi^{2}=139.9, p<0.001\right.$; Table 4$)$, and the interaction between site*species was significant $\left(\chi^{2}=189.9, p<0.001\right.$; Table 4$)$. Total recruitment peaked at the $2300 \mathrm{~m}$ site $(27.7 \pm 2.0 \%$;
Table 5) and was lower at the other three sites (ca. 12\%; Table 5), based on post hoc tests of the main-effect site $(p<0.001$; Fig. 2a, Supp. Table S2b).

All species collected at $2300 \mathrm{~m}$ were found to have the highest proportion of recruitment (\%) at their home sites (total 26.3 $\pm 2.7 \%$; Table 5, Supp. Table S3b).

With the exception of PoaBulbil, the total recruitment of species from the $2600 \mathrm{~m}$ home site was highest at the 


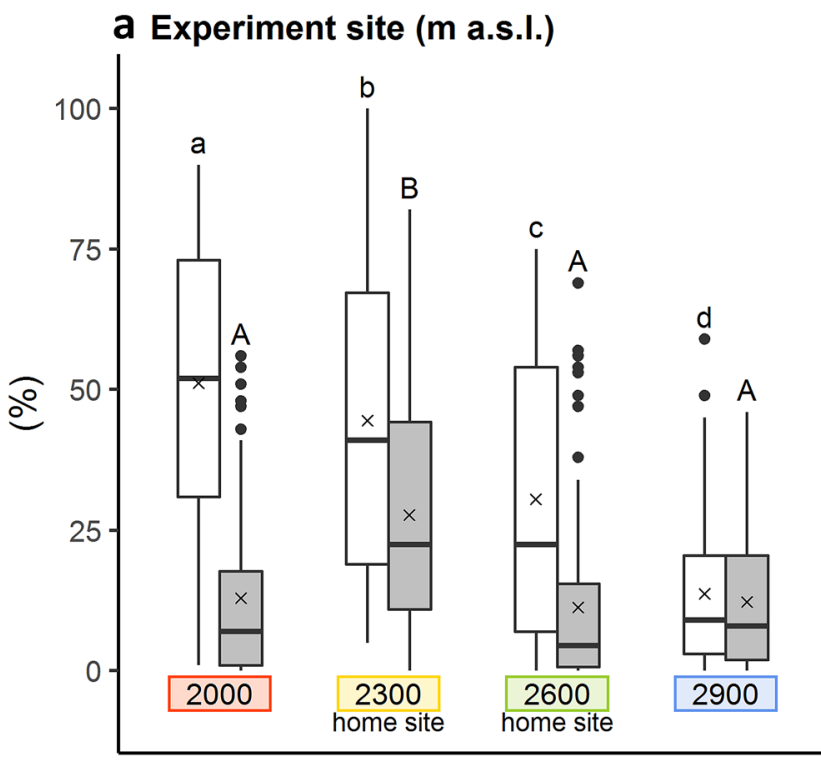

germination

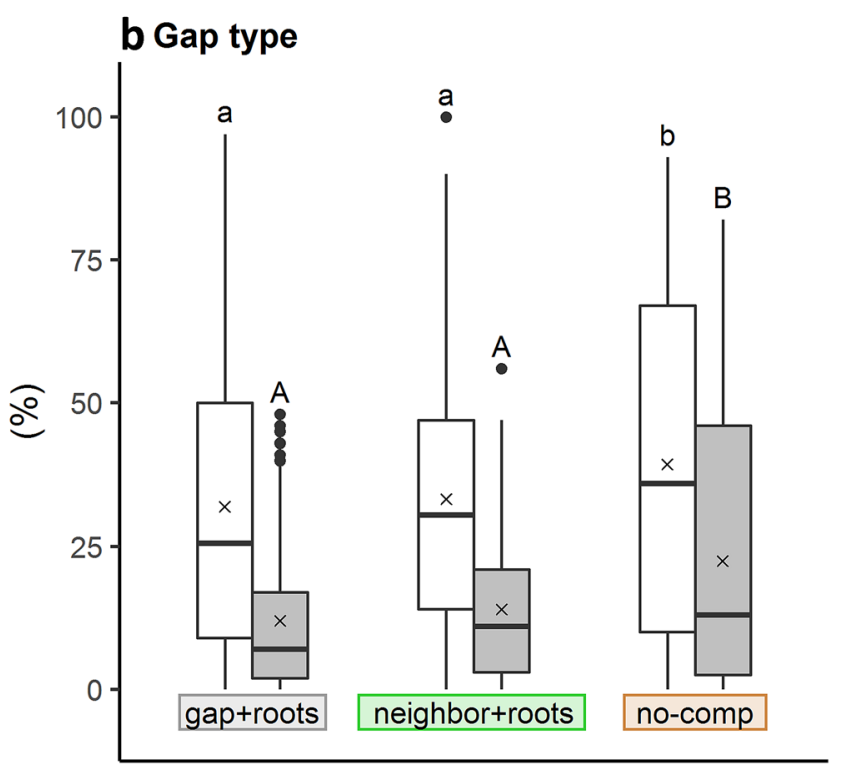

recruitment
Fig. 2 Total germination (white boxplots) and recruitment (grey boxplots) percentages a across experimental sites, and $\mathbf{b}$ in the gap types. The boxplot illustrates the first quantile and third quantile; error bars denote minima and maxima; points denote outliers; the horizontal line denotes the median; the cross denotes the mean. Different low-

$2300 \mathrm{~m}$ site $(30.1 \pm 3.0 \%$; Table 5), with approximately $10 \%$ more recruitment compared with the $2600 \mathrm{~m}$ home site (20.4 $\pm 3.5 \%$; Table 5, Fig. 2a). By performing post hoc tests of the beta regression between sites per species, we found that PoaBulbil recruited better at the home site than at the uppermost site ( $p<0.001$; Supp. Table S3b), and Leucanthemopsis recruited better at the home site than at the lowest site ( $p<0.001$; Supp. Table S3b).

\section{Gap effects}

Germination was influenced by the gap-type variable $\left(\chi^{2}=15.2, p=0.001\right.$; Table 4$)$, and the interaction effects of gap type* ${ }^{*}$ site $\left(\chi^{2}=77.5, p<0.001\right.$; Table 4$)$, gap type*species $\left(\chi^{2}=29.9, p<0.008\right.$; Table 4$)$, and gap type* ${ }^{*}$ site*species $\left(\chi^{2}=94.2, p<0.001\right.$; Table 4$)$ played a significant role. In total, germination was highest in 'no-comp', at $39.4 \pm 2.6 \%$ (Table 5 ), which was significantly higher than that in the other two gap types ( $p<0.001$; Fig. 2b). Germination in 'gap + roots' and 'neighbor + roots' did not differ from each other (Table 5; Fig. 2b).

Similarly, the gap-type variable significantly affected recruitment $\left(\chi^{2}=27.7, p<0.001\right.$; Table 4$)$, which was highest in 'no-comp' (22.4 $\pm 1.9 \%$; Table 5, Fig. 2b). No differences in recruitment occurred between the other two gap types $(11.9 \pm 1.1 \%$ and $13.9 \pm 1.2 \%$; Table 5 , Fig. $2 b)$. ercase letters denote significant differences between germination; different capital letters denote significant differences between recruitment, based on Bonferroni post hoc tests between the main factors site and gap type from beta regression models. For values of the significances, see Supp. Table S2

Gap-type effects on recruitment of each species are illustrated in Fig. 3 and were analyzed using post hoc comparisons per site (Supp. Table S4). Comparing 'no-comp' with 'gap + roots' at $2300 \mathrm{~m}$ (Supp. Table S4), significantly higher recruitment occurred for all species except for Мinuartia; i.e., Homogyne $(p<0.001)$, PoaSeeds $(p=0.02)$, Persicaria $(p<0.001)$, Silene $(p=0.001)$, Leucanthemopsis $(p=0.004)$, Agrostis $(p=0.037)$, and PoaBulbil $(p<0.001)$ under gap-type, 'no-comp' conditions. Similarly, comparing 'no-comp' with 'neighbor + roots' (Supp. Table S4), significantly higher recruitment at $2300 \mathrm{~m}$ was found for three species, i.e., Homogyne $(p<0.001)$, Persicaria $(p<0.001)$, and Silene $(p<0.001)$ under gap-type, 'no-comp' conditions.

Recruitment was further significantly higher in gap type, 'no-comp' than in the other two gap types at the $2600 \mathrm{~m}$ site for Leucanthemopsis $(p<0.001)$ and PoaBulbil $(p<0.001)$.

Regarding plant-plant interactions, PoaSeeds was the only species to germinate and recruit better in gaps with 'neighbor + roots' than in each of the other two gap types at the $2900 \mathrm{~m}$ site (Fig. 3a, Supp. Table S4). For completeness, the graph for gap effects on germination can be found in Supp. Material Fig. S3. 
a
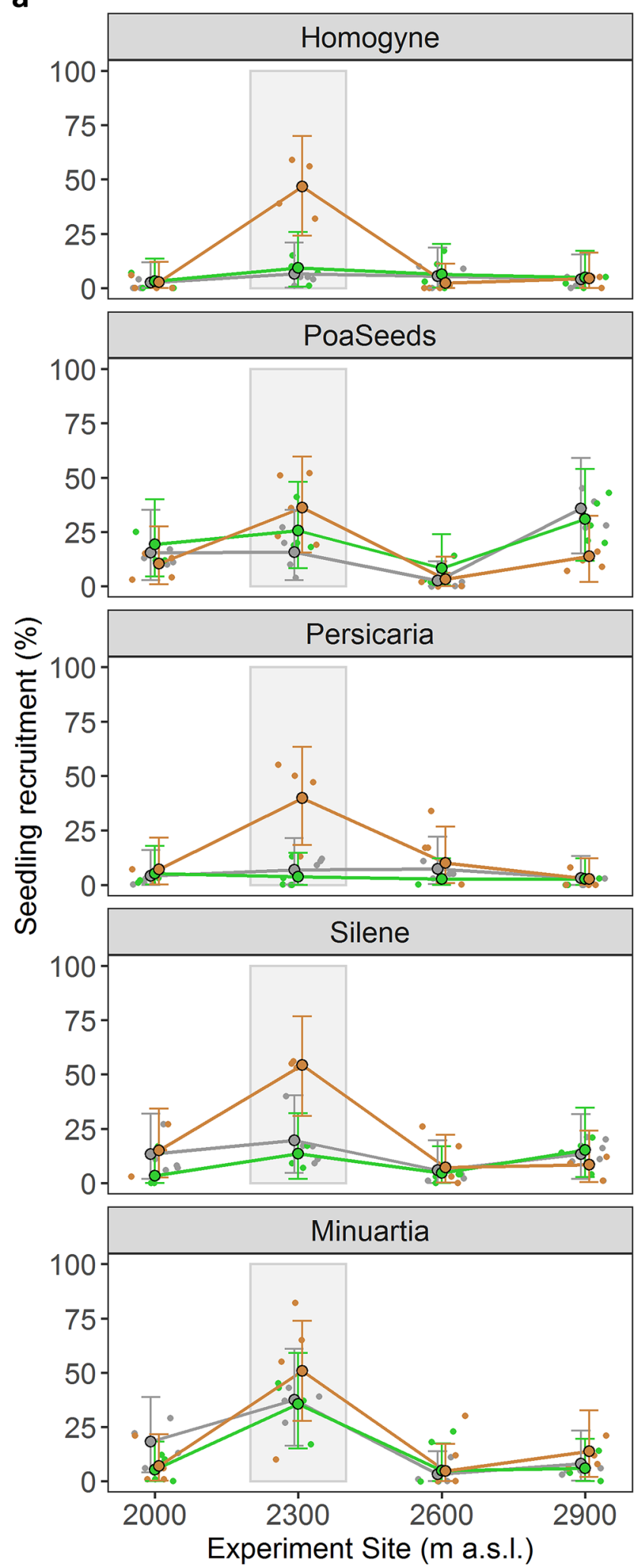

Fig. 3 Recruitment of each species in response to gap types across the stress-gradient profile of the experiment, illustrated for species from a home site $2300 \mathrm{~m}$ and $\mathbf{b}$ home site $2600 \mathrm{~m}$. Small points without border represent a scatterplot of field observations. Points with b
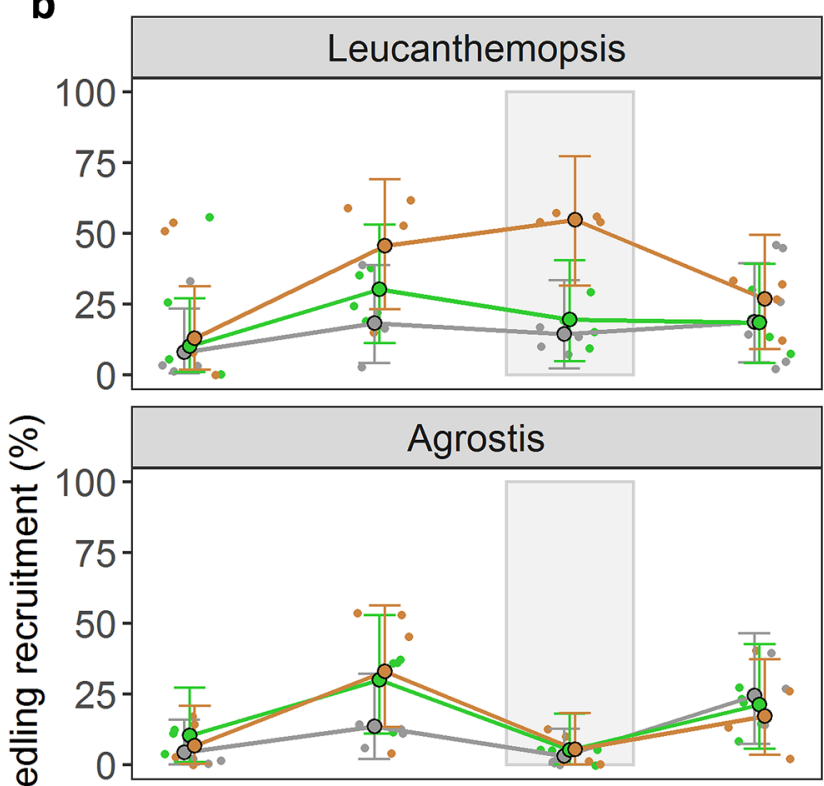

œ

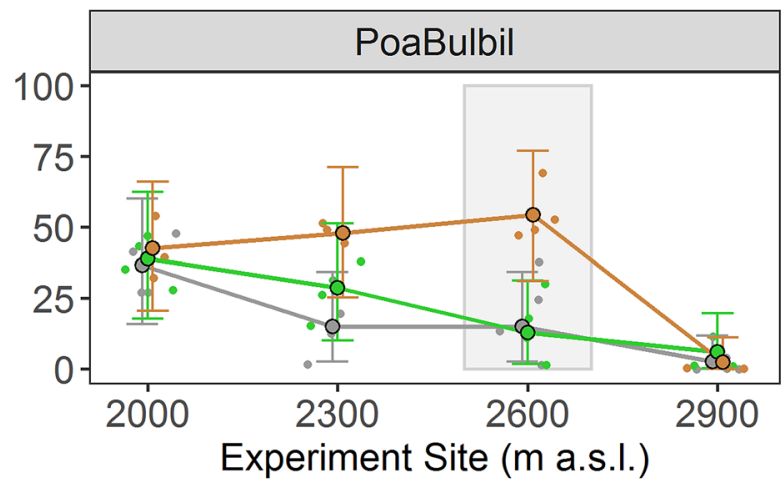

Gap type

-o- gap+roots

-o- neighbor+roots

no-comp border, connected by lines, illustrate the estimated means from the beta regression model; error bars denote the estimated quantiles (5\% and $95 \%$ ). Grey shaded areas highlight the home site of the species. For values of the significances, see Supp. Table S4 


\section{Vegetation cover, elevation and recruitment}

At the end of the experiment, the mean vegetation cover (i.e., top cover estimated in each experimental ring), averaged over all gap types, was $42.9 \pm 3.0 \%$ at the $2000 \mathrm{~m}$ site, $49.2 \pm 2.4 \%$ at the $2300 \mathrm{~m}$ site, $17.8 \pm 1.7 \%$ at the $2600 \mathrm{~m}$ site, and $10.1 \pm 0.7 \%$ at the $2900 \mathrm{~m}$ site.

Analyzed with beta regression, the overall vegetationcover effect on recruitment (\%) was significant $\left(\chi^{2}=74.5\right.$, $p<0.001$; Table 6), as were the site $\left(\chi^{2}=28.1, p<0.001\right.$; Table 6) and the interaction of vegetation cover*site $\left(\chi^{2}=56.1, p<0.001\right.$; Table 6$)$.

Vegetation cover did not influence seedling recruitment at the $2000 \mathrm{~m}$ and $2300 \mathrm{~m}$ sites $(p=0.170$ and $p=0.286$, respectively; Supp. Table S5), indicating that there was no significant increase in recruitment with increasing vegetation top cover. At these two sites, the vegetation cover in the rings ranged from 1 to $90 \%$ (Fig. 4). At $2600 \mathrm{~m}$, an increase in vegetation cover resulted in higher recruitment ( $p<0.001$; Supp. Table S5), with a maximum vegetation cover of $75 \%$ in one ring (Fig. 4). A vegetation-cover effect on recruitment was also seen at the uppermost site $(2900 \mathrm{~m}$, $p<0.001$; Supp. Table S5), where the maximum vegetation cover reached $28 \%$ in the two rings (Fig. 4).

\section{Discussion}

\section{Site and home-site effects}

Germination of the target species decreased with increasing elevation, independent of the home site (i.e., seed origin). Germination followed the temperature gradient with elevation, with a mean daily soil temperature of $13.9{ }^{\circ} \mathrm{C}$ decreasing to $8.2{ }^{\circ} \mathrm{C}$. Temperature is one of the most discussed impact factors on germination in alpine areas (Meineri et al. 2013; Klanderud et al. 2017; Fernández-Pascual et al. 2020; Anderson and Wadgymar 2020). Germination of alpine species is mainly triggered by alternating and warm temperatures in growth chambers (Schwienbacher et al. 2011; Walder and Erschbamer

Table 6 ANOVA-summary of the beta regression model testing recruitment in response to vegetation top cover, site (i.e., experimental sites incl. home sites), and the interaction term

\begin{tabular}{llcc}
\hline & $D f$ & Chisq & p value \\
\hline Top cover (Tc) & 8 & 74.54 & $<0.001$ \\
Site (S) & 6 & 28.09 & $<0.001$ \\
Tc x S & 6 & 56.11 & $<0.001$ \\
& Pseudo R-squared: 0.33 & \\
\hline
\end{tabular}

$D f$ degrees of freedom, Chisq value of the test statistic

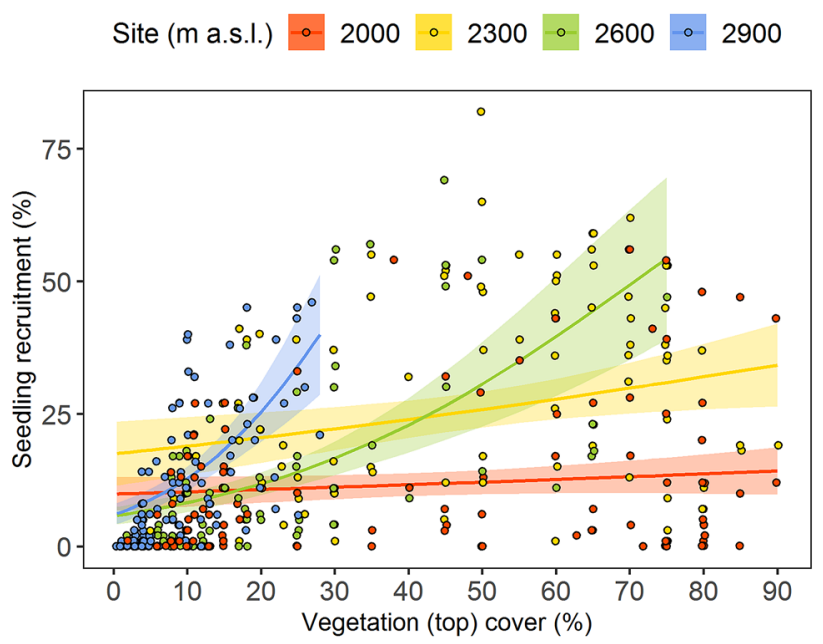

Fig. 4 Vegetation top cover effect on seedling recruitment at each experimental site, as a measure of vegetation growth within each experimental ring (i.e., target seedlings, central plant in ring, other seedlings, ingrowth form surrounding vegetation at the sites), at the end of the experiment. Points show a scatterplot of individual rings; lines represent the estimated mean recruitment per site from the beta regression; colored ribbons denote $95 \%$ confidence intervals. For values of the significances, see Supp. Table S5

2015; Tudela-Isanta et al. 2018; Margreiter et al. 2020). Recently, Fernández-Pascual et al. (2020) pointed out the positive effect of warm temperatures on alpine seed germination on a global scale. We can confirm this pattern for the overall germination proportion, specifically for six of the target species. However, there are also exceptions from this dominant pattern (e.g., Milbau et al. 2009; GiménezBenavides and Milla 2013), and two of our target species, Poa alpina (seeds and bulbils) and Persicaria, were exceptions in our experiment. They showed the highest germination at their home site $(2300 \mathrm{~m}$ a.s.1.). In a transplant experiment of alpine and boreal species in Norway, Meineri et al. (2013) recorded home-site effects for only one out of four species, while abiotic conditions (temperature and precipitation) at the transplant sites were more important for seedling recruitment. They further found reduced seedling emergence with increasing temperature $\left(+2{ }^{\circ} \mathrm{C}\right)$. In contrast, Mondoni et al. (2015) noted increased seedling emergence with increasing temperature $\left(+2.7^{\circ} \mathrm{C}\right)$ in an Italian glacier foreland and pointed out species-specific responses. This is in line with our results, with the highest germination proportion for most species occurring at the warmest site in the subalpine zone. However, all target species germinated at each site. Thus, a certain degree of intraspecific variability must be attributed to all target species.

Considering the total germination proportion, the home site had no significant effect. Similarly, Veselá et al. (2020) found no home-site effect on the germination of forty 
populations of Impatiens species in the Himalayas, but the home site was important for several interactions involving temperature and precipitation. Species-specific responses (see Suppl. Material) to the environment have been demonstrated in several studies investigating seedling responses to temperature (Graae et al. 2008; Milbau et al. 2009; Mondoni et al. 2015) and other abiotic factors (i.e., litter, soil, soil water content, and UV radiation; Sedlacek et al. 2015; Bosco et al. 2018).

In contrast to germination, recruitment turned out to be highest at the home site of species collected in the lower alpine zone (2300 $\mathrm{m}$ a.s.1.), but not for species collected in the upper alpine zone (2600 $\mathrm{m}$ a.s.l.). In the lower alpine zone, more than double of the seedlings recruited (ca. 28\%) compared with the other three sites (11-13\%). In addition to temperature, water availability is one of the most important factors for recruitment (Fenner and Thompson 2005; Walck et al. 2011). According to our measurements (Table 2), the standard defined permanent wilting point of plants (-1.5 MPa; Larcher 2003) was nearly reached; at $2000 \mathrm{~m}$ a.s.l. in 2017 and then in 2018 at all sites except $2900 \mathrm{~m}$ a.s.l. Drought has been identified to be the essential factor inhibiting recruitment in alpine environments (Stöcklin and Bäumler 1996; Venn and Morgan 2009; Walck et al. 2011); particularly on terrain without shelter, drought inhibits seedling recruitment (Stöcklin and Bäumler 1996). High recruitment in the lower alpine zone (2300 $\mathrm{m}$ a.s.1.) might be explained by the fact that the surrounding vegetation had laterally overgrown the rings, which possibly prevented desiccation of the soil surface. In contrast, at $2600 \mathrm{~m}$ a.s.l., drought became fully affective since the surrounding vegetation did not overgrow the rings. Furthermore, soil frost heaves were observed, which adds a limiting factor to seedling recruitment (Venn et al. 2009). The low performance of seedlings at $2000 \mathrm{~m}$ a.s.l. may be attributed to a reverse effect of the surrounding vegetation: here, the canopy grew up to a $15-50 \mathrm{~cm}$ height and shaded the rings. The emerged seedlings most likely suffered from light limitation (Galloway 2005).

The low recruitment at $2900 \mathrm{~m}$ a.s.l. is most plausibly explained by frost events in spring/summer. Such events have been identified as one of the reasons for high seedling mortality in alpine habitats (Venn et al. 2009; Marcante et al. 2012). In addition, the seedlings may have expressed reduced survival in response to high daily temperature fluctuations in the nival zone (Körner 2003; Kuhn et al. 2013).

The four experimental sites differed in environmental conditions, i.e., decreasing mean soil temperature and decreasing total vegetation cover with elevation and different soil conditions. When interpreting our results, we have to keep in mind that an experimental site comprises all these different components.

\section{Competition effects}

Gap creation had a significant effect on germination and recruitment $(\mathrm{H} 2)$. The highest germination and recruitment were recorded in the 'no-comp' gap type. As there were no germination and recruitment differences between the other two gap types with local soil ('gap + roots' and 'neighbor + roots'), we assume that the 'no-comp' effect may have been attributed to a release from competition. This underlines the hypothesis that competition-free gaps are important for alpine seedling recruitment (Venn et al. 2009; Cichini et al. 2011; Klanderud et al. 2017). Our results suggest that above- and belowground interactions occurred in 'neighbor + roots' and 'gap + roots'. Wilson (1993) already highlighted that belowground competition in the Snowy Mountains of Australia limited the growth of all investigated seedling species. Additionally, Venn et al. (2009) found negative belowground interactions on seedling growth when aboveground vegetation was removed along a stress gradient in the Australian Alps.

According to the stress-gradient hypothesis (Bertness and Callaway 1994; Callaway et al. 2002), a release of aboveground competition at low elevations (i.e., at the subalpine site in our study) should enhance germination and recruitment, while at high elevations, facilitative interactions should prevail. We expected that 'neighbor + roots' would facilitate seedling recruitment in the alpine and nival zones. However, this was not the case. Our results are in line with those from a calcareous grassland in Norway, where Klanderud et al. (2017) studied the effects of seedling recruitment by an aboveground removal experiment. The authors found no effects of neighboring plants; in contrast, recruitment was favored when aboveground vegetation was removed. Our experiment clearly showed that a release from complete competition (above- and belowground) significantly favored seedling emergence and recruitment along the entire stress gradient in our study area.

Regarding our experimental approach, we might argue that components of the local soil inhibited germination and recruitment. The local soil probably contained a considerable amount of organic compounds originating from dead material or root exudates from living plants (Fenner and Thompson 2005). Recently, Angers-Blondin et al. (2018) reported germination inhibition of Salix richardsonii (Salicaceae) seeds when exposed to allelopathic chemicals of Cassiope tetragona (Ericaceae) in alpine terrain. In contrast, Salix herbacea (Salicaceae) had no negative recruitment response when transplanted to soil with nonlocal microorganisms or to home-site soil (Sedlacek et al. 2014).

Soil parameters at the study sites did not differ much $(\mathrm{pH}$ and $\mathrm{C} / \mathrm{N}$; Table 3), with the exception that the $\mathrm{C} / \mathrm{N}$ ratio was lowest at the nival elevation site. A low $\mathrm{C} / \mathrm{N}$ ratio has been noted to release the greatest amount of inorganic nitrogen 
in decomposing litter, which enhanced seedling recruitment in an experimental trial on grasses and shrubs in Patagonia (Bosco et al. 2018). In contrast, litter with high $\mathrm{C} / \mathrm{N}$ ratios released less inorganic nitrogen. Following these ideas from the literature, a release from soil pathogens and chemical compounds (at least at the beginning of the experiment), combined with a possibly higher inorganic nitrogen supply and plenty of space, seems to be a reasonable explanation for the enhanced recruitment in the 'no-comp' gap type. Thus, speculatively, the release of belowground competition must have been most intense at the $2300 \mathrm{~m}$ site. However, the role of plant-soil feedbacks on recruitment, especially in alpine terrain, is largely unexplored. With these findings, we can partly confirm our H2, i.e., highest performance of seedlings in gaps without competition, but we cannot confirm this for the subalpine zone.

\section{Facilitation effects}

We hypothesized that recruitment might be favored in the 'neighbor + roots' gap type at the alpine and nival sites. However, facilitative interactions caused by neighboring plants did not occur at these sites. We are aware that we did not have full control (sowing in full aboveground vegetation); therefore, the results of 'neighbor + roots' have to be interpreted with caution. Several authors have reported neutral and positive interactions on plant growth and seedling recruitment at alpine elevations (Callaway et al. 2002; Venn et al. 2009; Cavieres et al. 2014; Wright et al. 2014; Klanderud et al. 2017). Venn et al. (2009) noted that the direction of interactions (positive, neutral, and negative) changed throughout the growing season. Similar observations were made by Wright et al. (2014), who reported varying interactions (competition and facilitation) during one observation period while studying the growth of pine seedlings in grassland communities in the USA as the ontogeny of the seedlings changed.

Due to the variation in local-site vegetation along the elevation gradient, different central plants were chosen for the 'neighbor + roots' gap type; however, mostly graminoids were used. We do not think that this fact reduces the power of the results. In their worldwide study, Callaway et al. (2002) showed that species-specific interactions did not interfere with the overall effect of competition at low elevations and facilitation at high elevations. Different neighboring species have also been used in other studies, such as grasses and shrubs (Venn et al. 2009) or grasses and herbs (Ryser 1993).

At $2900 \mathrm{~m}$ a.s.1., PoaSeeds recruited significantly better in the experimental gap types, 'gap + roots' and 'neighbor + roots', compared with 'no-comp', but there was no difference between the first two types. These results indicate that PoaSeeds had problems with the sterilized soil at the nival elevation site, probably because soil microorganisms did not invade as quickly as at lower study sites. Generally, low microorganism growth rates due to low temperatures are well known at high elevations (Bosco et al. 2018; Yang and van Elsas 2018). Poa alpina is commonly known to always have mycorrhizae as an adult plant in the study area (Erschbamer et al. 2012). Therefore, we assume that the local soil is particularly important for this species; however, approximately $15 \%$ of PoaSeeds managed to be recruited in the "nocomp' experiment at the uppermost site.

Clear facilitation effects were detected at the two uppermost elevation sites ( $2600 \mathrm{~m}$ and $2900 \mathrm{~m}$ a.s.1.) when vegetation top cover after 2 years was considered. Here, the established vegetation ameliorated abiotic conditions (i.e., drought, wind exposure, and frost) to a certain degree, while at lower sites, high vegetation cover impeded seedling recruitment (by shade and intensified competition). These findings corroborate the stress-gradient hypothesis (Bertness and Callaway 1994; Callaway et al. 2002; Anthelme et al. 2014). The vegetation cover in the rings reached a maximum of $28 \%$ at the uppermost site, in comparison to $90 \%$ at $2000 \mathrm{~m}$ and $2300 \mathrm{~m}$ a.s.l. In addition, the recruitment curve at $2600 \mathrm{~m}$ was much flatter than that at $2900 \mathrm{~m}$ a.s.l., suggesting that somewhere in between these cover maxima, a flip between positive and negative interactions occurred.

\section{Conclusions}

This experiment provides important data on alpine seedling recruitment in the field collected from sown seeds. Such data are relatively scarce for the European Alps. We confirm that germination and recruitment of alpine species are driven by the temperature gradient more than by home-site effects (a few exceptions occurred). This study further provides insights into plant-plant interactions during seedling recruitment. Only a complete release from competition enhanced germination and recruitment. As there were no significant differences between 'gap + roots' and 'neighbor + roots', we suggest that belowground competition was the critical driver for recruitment in this experiment. Furthermore, considering vegetation cover, an increase in top cover in the alpine and nival zones significantly facilitated seedling recruitment. Only in this case can a corroboration of the stress-gradient hypothesis be confirmed. The eight investigated species showed a relatively high intraspecific variability to cope with 'novel' environmental conditions at warmer and cooler sites. This may be considered a good prerequisite for adapting to future conditions.

Supplementary Information The online version contains supplementary material available at https://doi.org/10.1007/s00035-021-00264-9. 
Acknowledgements We are grateful to Moritz Falch, Julian Wimmer, Lena Nicklas, Mario Hörhager, and Angus Wylie, for preparing field material and/or helping in the field setup. We thank the team of the Botanical Garden Innsbruck, for advice and providing the soil mixture, and we thank Nadine Präg and Paul Illmer from the Department of Microbiology, University of Innsbruck, for determinations of the soil components. We further thank the Alpine Research Centre Obergurgl, namely Nikolaus Schallhart, for accommodation during the field trips and the support by requiring authorizations for the experimental sites. We also want to state our appreciation to the team of the University Centre Obergurgl, for a nice and uncomplicated collaboration. Lastly, we are grateful to three anonymous reviewers for their constructive statements and valuable suggestions that improved the manuscript.

Author contributions VM and BE conceived the idea and designed the study. VM carried out the experiment and collected data. VM analyzed the data with help from JW. VM and BE wrote the first draft, all authors contributed to further versions and the final manuscript.

Funding Open access funding provided by University of Innsbruck and Medical University of Innsbruck. This study was conducted within the 'Alpine Seed Conservation and Research Network' (http://www. alpineseedconservation.eu/), a project managed by the Royal Botanic Gardens Kew, funded by the 'David and Claudia Harding Foundation'. $\mathrm{VM}$ was additionally supported by a $\mathrm{PhD}$ scholarship grant from the University of Innsbruck (Doktoratsstipendium aus der Nachwuchsförderung, code: 2019/3/BIO-5).

Availability of data and material The datasets analyzed are available from the corresponding author.

\section{Declarations}

Conflict of interest The authors declare that they have no conflicts of interest.

Ethics approval The study did not cause any harm to the environment, animals, or plants.

Open Access This article is licensed under a Creative Commons Attribution 4.0 International License, which permits use, sharing, adaptation, distribution and reproduction in any medium or format, as long as you give appropriate credit to the original author(s) and the source, provide a link to the Creative Commons licence, and indicate if changes were made. The images or other third party material in this article are included in the article's Creative Commons licence, unless indicated otherwise in a credit line to the material. If material is not included in the article's Creative Commons licence and your intended use is not permitted by statutory regulation or exceeds the permitted use, you will need to obtain permission directly from the copyright holder. To view a copy of this licence, visit http://creativecommons.org/licenses/by/4.0/.

\section{References}

Aeschimann D, Lauber K, Moser DM, Theurillat J-P (2004) Flora alpina. Haupt Berne, Bern

Alexander JM, Diez JM, Levine JM (2015) Novel competitors shape species' responses to climate change. Nature 525:515-518. https:// doi.org/10.1038/nature14952
Alexander JM, Chalmandrier L, Lenoir J et al (2018) Lags in the response of mountain plant communities to climate change. Glob Chang Biol 24:563-579. https://doi.org/10.1111/gcb.13976

Anderson JT, Wadgymar SM (2020) Climate change disrupts local adaptation and favours upslope migration. Ecol Lett 23:181-192. https://doi.org/10.1111/ele.13427

Angers-Blondin S, Myers-Smith IH, Boudreau S (2018) Plant-plant interactions could limit recruitment and range expansion of tall shrubs into alpine and Arctic tundra. Polar Biol 41:2211-2219. https://doi.org/10.1007/s00300-018-2355-9

Anthelme F, Buendia B, Mazoyer C, Dangles O (2012) Unexpected mechanisms sustain the stress gradient hypothesis in a tropical alpine environment. J Veg Sci 23:62-72. https://doi.org/10.1111/j. 1654-1103.2011.01333.x

Anthelme F, Cavieres LA, Dangles O (2014) Facilitation among plants in alpine environments in the face of climate change. Front Plant Sci 5:1-15. https://doi.org/10.3389/fpls.2014.00387

Bertness MD, Callaway RM (1994) Positive interactions in communities. Trends Ecol Evol 9:191-193. https://doi.org/10.1016/01695347(94)90088-4

Bosco T, Bertiller MB, Carrera AL (2018) Abiotic factors affect the recruitment and biomass of perennial grass and evergreen shrub seedlings in denuded areas of Patagonian Monte rangelands. J Environ Manag 218:118-128. https://doi.org/10.1016/j.jenvman. 2018.04.020

Briceño VF, Hoyle GL, Nicotra AB (2015) Seeds at risk: How will a changing alpine climate affect regeneration from seeds in alpine areas? Alp Bot 125:59-68. https://doi.org/10.1007/ s00035-015-0155-1

Callaway RM, Brooker RW, Choler P et al (2002) Positive interactions among alpine plants increase with stress. Nature 417:844-848. https://doi.org/10.1038/nature00812

Cavieres LA, Brooker RW, Butterfield BJ et al (2014) Facilitative plant interactions and climate simultaneously drive alpine plant diversity. Ecol Lett 17:193-202. https://doi.org/10.1111/ele.12217

Cichini K, Schwienbacher E, Marcante S et al (2011) Colonization of experimentally created gaps along an alpine successional gradient. Plant Ecol 212:1613-1627. https://doi.org/10.1007/ s11258-011-9934-y

Cochrane A, Yates CJ, Hoyle GL, Nicotra AB (2015) Will amongpopulation variation in seed traits improve the chance of species persistence under climate change? Glob Ecol Biogeogr 24:12-24. https://doi.org/10.1111/geb.12234

Cribari-Neto F, Zeileis A (2010) Beta regression in R. J Stat Softw 34:1-24. https://doi.org/10.18637/jss.v034.i02

Donohue K, Rubio de Casas R, Burghardt L et al (2010) Germination, postgermination adaptation, and species ecological ranges. Annu Rev Ecol Evol Syst 41:293-319. https://doi.org/10.1146/annurevecolsys-102209-144715

Eriksson O, Ehrlén J (2008) Seedling recruitment and population ecology. In: Leck M, Parker V, Simpson R (eds) Seedling ecology and evolution. Cambridge University Press, Cambridge, pp 239-254. https://doi.org/10.1017/CBO9780511815133.013

Erschbamer B, Niederfriniger Schlag R, Winkler E (2008) Colonization processes on a central alpine glacier foreland. J Veg Sci 19:855-862. https://doi.org/10.3170/2008-8-18464

Erschbamer B, Bösch D, Fleisch M et al (2012) Keimung und Etablierung im Gletschervorfeld in Abhängigkeit von abiotischen und biotischen Faktoren. Berichte Der Reinhold Tüxen-Gesellschaft 24:89-102

Fenner M, Thompson K (2005) The ecology of seeds, 1st edn. Cambridge University Press

Fernández-Pascual E, Carta A, Mondoni A et al (2020) The seed germination spectrum of alpine plants: a global meta-analysis. New Phytol. https://doi.org/10.1111/nph.17086 
Fischer MA, Oswald K, Adler W (2008) Exkursionsflora von Österreich, Liechtenstein und Südtirol, 3rd edn. Land Oberösterreich, Biologiezentrum der Oberösterreichischen Landesmuseen, Linz

Galloway LF (2005) Maternal effects provide phenotypic adaptation to local environmental conditions. New Phytol 166:93-100. https:// doi.org/10.1111/j.1469-8137.2004.01314.x

Giménez-Benavides L, Milla R (2013) Comparative germination ecology of two altitudinal vicariant Saxifraga species endemic to the north of Spain. Plant Biol 15:593-600. https://doi.org/10.1111/j. 1438-8677.2012.00663.x

Gobiet A, Kotlarski S, Beniston M et al (2014) 21st century climate change in the European Alps-a review. Sci Total Environ 493:1138-1151. https://doi.org/10.1016/j.scitotenv.2013.07.050

Graae BJ, Alsos IG, Ejrnaes R (2008) The impact of temperature regimes on development, dormancy breaking and germination of dwarf shrub seeds from arctic, alpine and boreal sites. Plant Ecol 198:275-284. https://doi.org/10.1007/s11258-008-9403-4

Greig-Smith P (1983) Quantitavite plant ecology, 3rd edn. University of California Press, Berkeley

Harper JL (1977) Population biology of plants. Academic Press, London

Hothorn T, Zeileis A, Farebrother RW, et al (2019) Package "Imtest" Testing Linear Regression Models. https://cran.r-project.org/ web/packages/lmtest/lmtest.pdf. Accessed $22 \mathrm{Feb} 2021$

Hülber K, Bardy K, Dullinger S (2011) Effects of snowmelt timing and competition on the performance of alpine snowbed plants. Perspect Plant Ecol Evol Syst 13:15-26. https://doi.org/10. 1016/j.ppees.2011.01.001

Hupp N, Llambí LD, Ramírez L, Callaway RM (2017) Alpine cushion plants have species-specific effects on microhabitat and community structure in the tropical Andes. J Veg Sci 28:928938. https://doi.org/10.1111/jvs.12553

Jiménez-Alfaro B, Silveira FAO, Fidelis A et al (2016) Seed germination traits can contribute better to plant community ecology. J Veg Sci 27:637-645. https://doi.org/10.1111/jvs.12375

Klanderud K, Meineri E, Töpper J et al (2017) Biotic interaction effects on seedling recruitment along bioclimatic gradients: testing the stress-gradient hypothesis. J Veg Sci 28:347-356. https://doi.org/10.1111/jvs.12495

Körner C (2003) Alpine plant life. Functional plant ecology of high mountain ecosystems. Springer-Verlag

Kuhn M, Dreiseitl E, Emprechtinger M (2013) Temperatur und Niederschlag an der Wetterstation Obergurgl, 1953-2011. In: Koch EM, Erschbamer B (eds) Klima, Wetter, Gletscher im Wandel, 3rd edn. Innsbruck University Press, Innsbruck, pp 11-30

Larcher W (2003) Physiological plant ecology, 4th edn. SpringerVerlag, Berlin

Lenth R, Singmann H, Love J, et al (2019) 'package emmeans' Estimated Marginal Means, aka Least-Squares Means. https:// github.com/rvlenth/emmeans. Accessed 22 Feb 2021

Levy R (2014) Using R formulae to test for main effects in the presence of higher-order interactions. arxiv.org/abs/14052094

Marcante S, Sierra-Almeida A, Spindelböck JP et al (2012) Frost as a limiting factor for recruitment and establishment of early development stages in an alpine glacier foreland? J Veg Sci 23:858-868. https://doi.org/10.1111/j.1654-1103.2012.01411.x

Marcante S, Erschbamer B, Buchner O, Neuner G (2014) Heat tolerance of early developmental stages of glacier foreland species in the growth chamber and in the field. Plant Ecol 215:747-758. https://doi.org/10.1007/s11258-014-0361-8

Margreiter V, Pagitz K, Berg C et al (2020) Pros and cons of using a standard protocol to test germination of Alpine species. Plant Ecol. https://doi.org/10.1007/s11258-020-01061-w

Mayer R, Erschbamer B (2017) Long-term effects of grazing on subalpine and alpine grasslands in the Central Alps, Austria. Basic Appl Ecol. https://doi.org/10.1016/j.baae.2017.07.005
Meineri E, Spindelböck J, Vandvik V (2013) Seedling emergence responds to both seed source and recruitment site climates: a climate change experiment combining transplant and gradient approaches. Plant Ecol 214:607-619. https://doi.org/10.1007/ s11258-013-0193-y

Milbau A, Graae BJ, Shevtsova A, Nijs I (2009) Effects of a warmer climate on seed germination in the subarctic. Ann Bot 104:287296. https://doi.org/10.1093/aob/mcp117

Mondoni A, Pedrini S, Bernareggi G et al (2015) Climate warming could increase recruitment success in glacier foreland plants. Ann Bot 116:907-916. https://doi.org/10.1093/aob/mcv101

R Core Team (2020) R: a language and environment for statistical computing. In: R Found. Stat. Comput. Vienna, Austria. https:// www.r-project.org/. Accessed 11 Jun 2021

Rosbakh S, Poschlod P (2015) Initial temperature of seed germination as related to species occurrence along a temperature gradient. Funct Ecol 29:5-14. https://doi.org/10.1111/1365-2435. 12304

RStudio Team (2020) RStudio: integrated development for R. In: RStudio, Inc., Boston, MA. https://rstudio.com. Accessed 11 June 2021

Ryser P (1993) Influences of neighbouring plants on seedling establishment in limestone grassland. J Veg Sci 4:195-202. https://doi.org/ $10.2307 / 3236105$

Schwienbacher E, Navarro-Cano JA, Neuner G, Erschbamer B (2011) Seed dormancy in alpine species. Flora Morphol Distrib Funct Ecol Plants 206:845-856. https://doi.org/10.1016/j.flora.2011. 05.001

Sedlacek JF, Bossdorf O, Cortés AJ et al (2014) What role do plantsoil interactions play in the habitat suitability and potential range expansion of the alpine dwarf shrub Salix herbacea? Basic Appl Ecol 15:305-315. https://doi.org/10.1016/j.baae.2014.05.006

Sedlacek J, Wheeler JA, Cortés AJ et al (2015) The response of the alpine dwarf shrub Salix herbacea to altered snowmelt timing: Lessons from a multi-site transplant experiment. PLoS ONE. https://doi.org/10.1371/journal.pone.0122395

Shimono Y, Kudo G (2003) Intraspecific variations in seedling emergence and survival of Potentilla matsumurae (Rosaceae) between alpine fellfield and snowbed habitats. Ann Bot 91:21-29. https:// doi.org/10.1093/aob/mcg002

Smithson M, Verkuilen J (2006) A better lemon squeezer? Maximumlikelihood regression with beta-distributed dependent variables. Psychol Methods 11:54-71. https://doi.org/10.1037/1082-989X. 11.1.54

Steiner BL, Armbruster GFJ, Scheepens JF, Stöcklin J (2012) Distribution of bulbil- and seed-producing plants of Poa alpina (Poaceae) and their growth and reproduction in common gardens suggest adaptation to different elevations. Am J Bot 99:2035-2044. https://doi.org/10.3732/ajb.1200213

Stöcklin J, Bäumler E (1996) Seed rain, seedling establishment and clonal growth strategies on a glacier foreland. J Veg Sci 7:45-56. https://doi.org/10.2307/3236415

Stöcklin J, Kuss P, Pluess AR (2009) Genetic diversity, phenotypic variation and local adaptation in the alpine landscape: case studies with alpine plant species. Bot Helv 119:125-133. https://doi.org/ 10.1007/s00035-009-0065-1

Tudela-Isanta M, Ladouceur E, Wijayasinghe M et al (2018) The seed germination niche limits the distribution of some plant species in calcareous or siliceous alpine bedrocks. Alp Bot 128:83-95. https://doi.org/10.1007/s00035-018-0199-0

Venn SE, Morgan JW (2009) Patterns in alpine seedling emergence and establishment across a stress gradient of mountain summits in south-eastern Australia. Plant Ecol Divers 2:5-16. https://doi. org/10.1080/17550870802691356

Venn S, Morgan J, Green P (2009) Do facilitative interactions with neighboring plants assist the growth of seedlings at high altitudes 
in alpine Australia? Arctic Antarct Alp Res 41:381-387. https:// doi.org/10.1657/1938-4246-41.3.381

Veselá A, Dostálek T, Rokaya MB, Münzbergová Z (2020) Seed mass and plant home site environment interact to determine alpine species germination patterns along an elevation gradient. Alp Bot 130:101-113. https://doi.org/10.1007/s00035-020-00242-7

Walck JL, Hidayati SN, Dixon KW et al (2011) Climate change and plant regeneration from seed. Glob Chang Biol 17:2145-2161. https://doi.org/10.1111/j.1365-2486.2010.02368.x

Walder T, Erschbamer B (2015) Temperature and drought drive differences in germination responses between congeneric species along altitudinal gradients. Plant Ecol 216:1297-1309. https://doi.org/ 10.1007/s11258-015-0509-1

Wickham H, Averick M, Bryan J et al (2019) Welcome to the Tidyverse. J Open Source Softw 4:1686. https://doi.org/10.21105/ joss.01686

Wilke CO (2018) cowplot: Streamlined Plot Theme and Plot Annotations for "ggplot2". R package version 1.1.0. https://cran.r-proje ct.org/package=cowplot. Accessed 22 Feb 2021
Wilson SD (1993) Competition and Resource Availability in Heath and Grassland in the Snowy Mountains of Australia. J Ecol 81:445. https://doi.org/10.2307/2261523

Wright A, Schnitzer SA, Reich PB (2014) Living close to your neighbors: The importance of both competition and facilitation in plant communities. Ecology 95:2213-2223. https://doi.org/10.1890/ 13-1855.1

Yang P, van Elsas JD (2018) Mechanisms and ecological implications of the movement of bacteria in soil. Appl Soil Ecol 129:112-120. https://doi.org/10.1016/j.apsoil.2018.04.014

Publisher's Note Springer Nature remains neutral with regard to jurisdictional claims in published maps and institutional affiliations. 